\begin{tabular}{c} 
Volume and Issues Obtainable at Center for Sustainability Research and Consultancy \\
Journal of Business and Social Review in Emerging Economies \\
ISSN: 2519-089X \& ISSN (E): 2519-0326 \\
Volume 7: Issue 4 December 2021 \\
CSRᄃ \\
Journal homepage: www.publishing.globalcsrc.org/jbsee \\
\hline
\end{tabular}

\title{
Investigation of Cognitive Mapping Abilities of Persons with Visual Impairment
}

Rabia Awan, MPhil Scholar, University of the Punjab, Lahore, Pakistan

*Ghulam Fatima, Associate Professor, University of the Punjab, Lahore, Pakistan

Muhammad Jahanzaib, Phd Scholar, University of the Punjab, Lahore, Pakistan

*Corresponding author's email address: fatima.dse@ @u.edu.pk

\begin{tabular}{l}
\hline ARTICLE DETAILS \\
\hline History \\
Revised format: Nov 2021 \\
Available Online: Dec 2021 \\
\hline Keywords \\
Cognitive Mapping Abilities, \\
Investigation,Persons with \\
Visual Impairment. \\
\hline
\end{tabular}

JEL Classification

D91, E71

\section{OPEN ACCESS}

\begin{abstract}
Purpose: Cognitive mapping of spaces is vital to the progress of well-organized orientation and mobility skills. Mostly the information required for cognitive mapping is acquired through the sense of vision. Persons with visual impairment lack in this critical information, and in consequence, they face difficulties in mapping as well as navigating new spaces. This study was aimed to investigate the cognitive mapping abilities of persons with visual impairment for the purpose of improvement in their
\end{abstract} independent movement.

Design/Methodology/Approach: The population of this quantitative study comprised persons with visual impairment residing in district Lahore, Pakistan. The convenient sampling technique was used for taking the sample of 30 persons having visual impairment. A self-developed questionnaire (Cronbach Alpha: 0.78) consisting of 36 items on five-point Likert scale (strongly agree to strongly disagree) was used to gather data through online mode. Descriptive and inferential statistics were used to analyze data.

Findings: The findings of the study revealed that the persons with visual impairment used language audition and haptics to get a direct or indirect awareness of their physical environment. The usage of assistive devices play an important role in their lives.

Implications/Originality/Value: The study suggested the strong need to assess the cognitive mapping abilities of persons with visual impairment through an increased sample and experimentation to improve their quality of life by increasing mobility and independence.

(C) 2021 The authors, under a Creative Commons AttributionNon Commercial- 4.0

Recommended citation: Awan, R., Fatima, G. and Jahanzaib, M. (2021). Investigation of Cognitive Mapping Abilities of Persons with Visual Impairment. Journal of Business and Social Review in Emerging Economies, 7 (4), 1051-1059. 


\section{Introduction}

Cognitive mapping is a mental perception of an environment, formulated through trial and error along with observation. The assumption that works behind this concept is that an individual looks for and gather contextual clues, such as environmental relationships, rather than acting as a passive receptor of information needed to achieve a goal. Human beings and animals too have fully grown cognitive maps that consist of spatial information enabling them to orient themselves and seek their way in the real world. Symbolism and meaning are also part of such maps. The utility of the cognitive map would be associated with success to reach the objective points in the real environment (Guerrón, Coboa, Olmedoa, \& Martína,2020). Whether blind, visually impaired, or sighted, our quality of life is greatly dependent on our ability to make informed spatial decisions through the processing and synthesis of spatial information, within a variety of situations, at differing scales (Golledge, 1993).

To varying extents, we all have a spatial awareness of our surroundings. Through the varied stimulation of our senses, we come to know about places in the world. These sensory inputs emerge directly from the environment, where our senses engage in direct perception with objects that are close enough to touch, taste, smell, hear and see (Jacobson,1998). The ability to navigate spaces independently, safely, and efficiently is a combined product of motor, sensory and cognitive skills. Normal exercise of this ability directly affects the individual's quality of life. Mental mapping of spaces, and of the possible paths for navigating these spaces, is essential for the development of efficient orientation and mobility skills (Lahav \& Mioduser, 2003). Most of the information required for this mental mapping is gathered through the visual channel (Lynch, 1960).

Blind people are lagging in this information, as a result, they encounter great difficulties like developing efficient mental maps of spaces, and so navigating efficiently within these spaces. Blind persons might have difficulties in estimating distances and inferring spatial relationships in large spaces (Luca, Fabrizio, Vigini, \& Cocchi,2019).

In the first place, an individual with visual impairment is a human, a bio-psycho-socio-spiritual being. For such a person, spatial orientation is considerably affected by visual impairment, external and internal aspects. At the same time, spatial mobility is dependent upon training lower and higher compensatory functions. For successful orientation, such person develops a spatial mental/cognitive map. In this sense, the mental mapping process and the form of the mental map have certain specifics (Majerova, 2014). Sound and soundscape have a supportive role for memory and, thus, enable storage and recall of spatial information (Papadopoulosa, Baroutib \& Koustriavac, 2018). Furthermore, prior exploration of an environment by persons with visual impairment can increase their spatial knowledge without the risks and cognitive load of direct exploration (Guerreiro, Ahmetovic1, Kitani, \& Asakawa1,2017).

The world has many dimensions for a person having visual impairment. These dimensions are implied to receive and process information of different types of quality and quantity. As the information theory describes that, this involves a comprehensive approach to an individual in the context of bio-psycho-socio-spiritual information aspect. In special education, the information aspect is closely related to compensation. Compensation is taken as a replacement for decreased performance of an organ through increasing another one. Lower compensatory functions include hearing, touch, smell, and taste; higher compensatory functions include memory, attention, thinking and imagination (Edelsberger et al., 2000). This infers that the process of spatial mental mapping involves hearing, touch, smell, and taste as well as memory, attention, thinking and imagination. Similarly, will and emotion significantly affect the way an individual uses information in the development of a mental map (Majerova, 2014). 
The process of spatial mental mapping is defined by four basic stages: 1. Obtaining information through the senses. 2. Selection and conscious processing.

3. Storage in the form of spatial representation. 4. Decision making, movement and orientation based on the stored representation. Investigating the cognitive mapping skills of persons with visual impairment has considerable theoretical and practical importance. It has four major applied reasons. First, through this investigation it is possible to enhance the life quality of people who are visually impaired or blind through increased mobility and independence. Cognitive mapping research has the prospects to provide clues about improving visually impaired people's wayfinding and orientation skills, by directly effecting orientation, mobility, and rehabilitation training, and eventually on independence and quality of life (Papadopoulosa, Baroutib \& Koustriavac, 2018).

The ability to travel independently and to interact with the wider world is one of the greatest challenges facing persons with visual impairment (Golledge, 1993). Indeed, Bruce et al., (1991) found in a survey of young people registered blind in the U.K. that in the preceding week, 20 per cent of respondents had not left their home, only 34 per cent had travelled locally, and only 41 per cent left the confines of the home alone and on foot. Second, an increasing number of blind and visually impaired persons use mobility devices. For the effective and efficient work of these devices, it is important that into their conception and design goes a baseline awareness about the navigation of visually impaired and blind people without these aids. Cognitive mapping research can come up with this baseline, providing what information is required by a blind navigator and how can we present this information to a traveler. Cognitive mapping research can also be used to evaluate the utility and benefits of these assistive devices. Third, the planning of easier to remember and more pleasurable to use environments can be facilitated by using the perceptions and insights obtained through cognitive mapping research. We can better plan, design and manage the environment for and with people if we know how they imagine the world.

Fourth, through this study, we can obtain valuable information concerning the role of sensory experience in cognitive mapping in general. This leads to theoretical insights in human thought and could have implications to other projects relating to wayfinding such as robotics and artificial intelligence (Kuipers,1997).

The long history of research about cognitive mapping abilities of blind people is categorized by Fletcher (1980) into three broad theories: deficiency, inefficiency, and difference. The deficiency theory states that individuals who are congenitally blind, are not able to formulate a general spatial understanding because they have never experienced the perceptual processes (e.g., vision) required to comprehend complex spatial arrangements. The inefficiency theory states that the knowledge and comprehension of people with visual impairments about spatial concepts is inferior to that based upon vision, because information is based upon auditory and haptic cues. But it does not mean that blind people cannot understand and mentally manipulate spatial concepts. The difference theory proposes that visually impaired individuals possess the same abilities to process and understand spatial concepts, and that though functionally equivalent to the sighted, they are carried out in a different and often slower manner (Juurmaa, 1973). Millar (1988) argues that although nonvisual senses are inferior to coding spatial relational information, visually impaired people have no less potential than the sighted for developing a fully integrated representation of space.

\section{Objectives of the Study}

The study was intended to:

1. To determine the role of sensory experiences in cognitive mapping of blind persons.

2. To find out the utility and benefits of assistive devices used for mobility.

3. To use the insights and understanding obtained through cognitive mapping for the 
modification of existing environment.

4. To find out the information needed by a blind navigator.

\section{Questions of the Study}

The questions of the study included:

1. What is the role of sensory experiences in development of cognitive mapping abilities of blind people?

2. What are the benefits of assistive devices used for mobility?

3. How can an existing environment be modified to improve the mobility and independence of persons with visual impairment?

\section{Method}

The following method was used:

\section{Participants}

In this descriptive type of study, 35 persons with visual impairment living in Lahore participated. The sample consisted of 18 males and 17 females. Their age ranged from 14 years to 52 years $(\mathrm{M}=23.6)$. All the participants had legal blindness. Specifically, 18 participants had total blindness or light perception, and 10 participants had profound visual impairments (their visual acuity was less than 1/40), four participants were having moderate level of visual impairment, three participants had low vision. The visual impairment was congenital for 14(40\%) participants and acquired for the remaining 21(60\%) participants. All the participants were educated and currently studying or doing jobs. The sample was collected through convenient sampling technique. Convenient sampling is about collecting sample from the population that is near and approachable to the researcher. It is also known as accidental sampling, opportunity sampling, or grab sampling because the researchers can use the respondents who are conveniently available.

\section{Instrumentation and Procedure}

A survey was conducted through a self-developed questionnaire. At initial level, 45 items were developed. After pilot testing nine items were removed due to affecting reliability of the questionnaire which was finalized with 36 items (Cronbach Alpha 0.78). The questionnaire was divided into seven parts a) demographic information b) importance of haptic information for appropriate spatial performance (4 items) c) importance of auditory information for appropriate spatial performance (4 items) d) disadvantage due to lack of vision (3 items) e) importance of the assistive devices made for mobility (6 items)

f) Physical barriers of the environment (9 items) g) self-confidence about cognitive mapping skills and independent movement (6 items). The validity of the questionnaire was ensured through gathering opinions of three experts working in the field of visual impairment and having research exposure.

The data was collected through online mode. Initially the contact numbers and email addresses of the

Persons with visual impairment were sought. Their consent to be a part of this study was obtained. They were assured that information taken from them will be kept confidential and will only be used for research purposes. The questionnaires were sent to them through email which they returned after a few days. It took almost 12 days in receiving back all questionnaires.

\section{Data Analysis}

The data was analyzed using descriptive statistics in the form of percentages based on five categories: Strongly agree, Agree, Uncertain, Disagree and Strongly disagree. 


\section{Results}

Table 1

Frequency Distribution of Responses on Haptic Information

\begin{tabular}{|c|c|c|c|c|c|c|}
\hline & Items & $\mathbf{S A}$ & $\mathbf{A}$ & $\mathbf{N}$ & D & SD \\
\hline 1 & $\begin{array}{l}\text { Haptic information is essential for } \\
\text { appropriate spatial performance. }\end{array}$ & $42.9 \%$ & $45.7 \%$ & $5.7 \%$ & 2.8 & $2.8 \%$ \\
\hline 2 & $\begin{array}{l}\text { I rely on using palms and fingers for fine } \\
\text { recognition of objects. }\end{array}$ & $38.2 \%$ & $41.2 \%$ & $20.6 \%$ & 0 & 0 \\
\hline 3 & $\begin{array}{l}\text { I can have the exact information about } \\
\text { surface by my feet. }\end{array}$ & $18.2 \%$ & $45.5 \%$ & $12.1 \%$ & $18.2 \%$ & $6.1 \%$ \\
\hline 4 & $\begin{array}{l}\text { The information gained through tactile } \\
\text { sense is better than that is gained through } \\
\text { vision. }\end{array}$ & $11.8 \%$ & $35.3 \%$ & $14.7 \%$ & $32.4 \%$ & $5.9 \%$ \\
\hline
\end{tabular}

Table 1 depicts that majority of the persons having visual impairment rely on haptic information for appropriate spatial information as more than $77 \%$ respondents fall in the category of strongly agree and agree in the answer of statement \# 1,2, and 3.but more than $50 \%$ respondents disagree, or they are uncertain that this information is better than the information gained through vision.

Table 2

Frequency Distribution of Responses of Persons with Visual Impairment on Using Auditory Channel for Special Skills

\begin{tabular}{|c|c|c|c|c|c|c|}
\hline & Items & SA & $\mathbf{A}$ & $\mathbf{N}$ & D & SD \\
\hline 1 & $\begin{array}{l}\text { I can know about the distance of anything } \\
\text { (animal, human, machine) by hearing its } \\
\text { sound. }\end{array}$ & $20.6 \%$ & $70.6 \%$ & $2.9 \%$ & $5.9 \%$ & 0 \\
\hline 2 & $\begin{array}{l}\text { I can know about the presence of other } \\
\text { people (machine or animal) through } \\
\text { auditory channel. }\end{array}$ & $38.2 \%$ & $52.9 \%$ & $4.4 \%$ & $4.5 \%$ & 0 \\
\hline 3 & $\begin{array}{l}\text { I can have the complementary information } \\
\text { about an event with the help of my auditory } \\
\text { skills. }\end{array}$ & $24.2 \%$ & $54.5 \%$ & $15.2 \%$ & $6.1 \%$ & 0 \\
\hline 4 & $\begin{array}{l}\text { Audio information is superior to all other } \\
\text { sensory alternatives in development of } \\
\text { spatial skills. }\end{array}$ & $35.3 \%$ & $50 \%$ & $5.9 \%$ & $8.8 \%$ & 0 \\
\hline
\end{tabular}

Table 2 reveals that persons having visual impairment mostly rely on the information gained through auditory channel as more than $85 \%$ respondents consider audio information as superior to all other sensory alternatives in development of spatial skills.

Table 3

Frequency Distribution of Responses of Persons with Visual Impairment on Vision Regarding Spatial Relational Information

\begin{tabular}{llllll}
\hline Items & SA & A & N & D & SD \\
\hline $\begin{array}{l}\text { vision is more important to code spatial relational } \\
\text { information? }\end{array}$ & $32.4 \%$ & $47.1 \%$ & $8.8 \%$ & $5.8 \%$ & $5.9 \%$ \\
\hline
\end{tabular}




\begin{tabular}{|c|c|c|c|c|c|c|}
\hline 2 & $\begin{array}{l}\text { I consider the vision as necessary element to } \\
\text { comprehend complex spatial arrangements }\end{array}$ & $14.7 \%$ & $50 \%$ & $8.8 \%$ & $23.5 \%$ & $3 \%$ \\
\hline 3 & $\begin{array}{l}\text { It is very difficult to acquire complex information about } \\
\text { objects without vision }\end{array}$ & $20.6 \%$ & $50 \%$ & $17.6 \%$ & $11.8 \%$ & 0 \\
\hline
\end{tabular}

Table 3 shows that respondents consider the loss of vision as a big disadvantage to code spatial relational information.

Table 4

Frequency Distribution of Responses of Persons with Visual Impairment on the usefulness of Assistive Devices

\begin{tabular}{lllllll}
\hline Items & SA & A & N & D & SD \\
\hline 1 & $\begin{array}{l}\text { Assistive devices are helpful in avoiding obstacles } \\
\text { within the next few spaces. }\end{array}$ & $28.1 \%$ & $56.3 \%$ & $6.2 \%$ & $9.4 \%$ & 0 \\
2 & $\begin{array}{l}\text { These devices detect hazards in the environment. } \\
\text { I rely on cane for scanning the immediate }\end{array}$ & $5.9 \%$ & $64.7 \%$ & $20.6 \%$ & $8.8 \%$ & 0 \\
$\begin{array}{l}\text { surroundings. } \\
4\end{array}$ & $\begin{array}{l}\text { Assistive devices play an important role in my life. } \\
\text { Assistive devices enhance all type of performance in new }\end{array}$ & $20.6 \%$ & $61.2 \%$ & $29.4 \%$ & $11.8 \%$ & 0 \\
$\begin{array}{l}\text { spaces. } \\
6\end{array}$ & $52.9 \%$ & $11.8 \%$ & 0 & 0 \\
These devices are important for independent mobility. & $18.2 \%$ & $63.6 \%$ & $14.1 \%$ & $2.9 \%$ & 0 \\
\hline
\end{tabular}

Table 4 depicts that more than $75 \%$ respondents agree with the high utility and benefits of assistive devices while performing in new spaces. So, it is essential to add baseline awareness of how visually impaired and blind people navigate without these aids in the conception and designing of assistive devices.

Table 5

Frequency Distribution of Responses of Persons with Visual Impairment Regarding Physical Obstacles

\begin{tabular}{|c|c|c|c|c|c|c|}
\hline & Items & SA & $\mathbf{A}$ & $\mathbf{N}$ & D & SD \\
\hline 1 & $\begin{array}{l}\text { Pavement furniture creates problems } \\
\text { while moving independently. }\end{array}$ & $20.6 \%$ & $44.1 \%$ & $14.7 \%$ & $20.6 \%$ & 0 \\
\hline 2 & $\begin{array}{l}\text { Construction/repair also causes } \\
\text { problems. }\end{array}$ & $38.2 \%$ & $52.9 \%$ & $3 \%$ & $5.9 \%$ & 0 \\
\hline 3 & $\begin{array}{l}\text { Irregular, uneven, or broken surface is } \\
\text { an obstacle. }\end{array}$ & $52.9 \%$ & $35.3 \%$ & $3 \%$ & $8.8 \%$ & 0 \\
\hline 4 & $\begin{array}{l}\text { Crowds of people is always an } \\
\text { obstacle. }\end{array}$ & $27.3 \%$ & $51.5 \%$ & $12.1 \%$ & $6.1 \%$ & $3 \%$ \\
\hline 5 & Using steps is not an issue. & 29.4 & 55.9 & 2.9 & 11.8 & 0 \\
\hline 6 & $\begin{array}{l}\text { Weather is a factor that affects } \\
\text { independent movement and } \\
\text { spatial cognition skills. }\end{array}$ & $11.8 \%$ & $67.6 \%$ & $11.8 \%$ & $4.8 \%$ & $4 \%$ \\
\hline 7 & $\begin{array}{l}\text { Lack of railing affects independent } \\
\text { movements. }\end{array}$ & $29.4 \%$ & $35.3 \%$ & $17.6 \%$ & $14.7 \%$ & $3 \%$ \\
\hline 8 & Traffic lights should be audible & $52.9 \%$ & $32.4 \%$ & $2.95 \%$ & $8.8 \%$ & $2.95 \%$ \\
\hline 9 & $\begin{array}{l}\text { Visual cues (e.g., street signs) should } \\
\text { be audible. }\end{array}$ & $47.1 \%$ & $29.4 \%$ & $14.7 \%$ & $8.8 \%$ & 0 \\
\hline
\end{tabular}

Table 5 illustrates some of the physical problems encountered when navigating through the built environment without sight. More than $70 \%$ respondents consider the pavement furniture, construction/repair, irregular, uneven or broken surface, Lack of railing, and weather as big factors affecting independent movement and spatial cognition skills. About $12 \%$ respondents consider the usage of stairs creating problem for them. Almost $80 \%$ respondents suggested to design the audible traffic lights and visual cues. These insights 
may be used to facilitate the planning of environments that are easier to remember and more pleasurable to use.

Table 6

Frequency Distribution of Responses of Persons with Visual Impairment Regarding Spatial Concepts

\begin{tabular}{|c|c|c|c|c|c|c|}
\hline & Items & S.A & $\mathbf{A}$ & $\mathbf{N}$ & D & S.D \\
\hline 1 & $\begin{array}{l}\text { I can understand and mentally } \\
\text { manipulate spatial concepts. }\end{array}$ & $14.7 \%$ & $29.4 \%$ & $32.4 \%$ & $23.5 \%$ & 0 \\
\hline 2 & $\begin{array}{l}\text { The acquisition of knowledge } \\
\text { of an environment's structural } \\
\text { realities is more like an } \\
\text { achievement. }\end{array}$ & $14.7 \%$ & $67.6 \%$ & $8.8 \%$ & $8.8 \%$ & 0 \\
\hline 3 & $\begin{array}{l}\text { The ability to travel } \\
\text { independently and to interact } \\
\text { with the wider world is one of } \\
\text { the greatest challenges. }\end{array}$ & $35.3 \%$ & $35.3 \%$ & $5.9 \%$ & $14.7 \%$ & $8.8 \%$ \\
\hline 4 & $\begin{array}{l}\text { I can move outside the house } \\
\text { independently. }\end{array}$ & $17.6 \%$ & $32.4 \%$ & $11.8 \%$ & $35.3 \%$ & $2.9 \%$ \\
\hline 5 & $\begin{array}{l}\text { I always use the familiar route to } \\
\text { go to the same place. }\end{array}$ & $2.8 \%$ & $32.4 \%$ & $20.6 \%$ & $32.4 \%$ & $11.8 \%$ \\
\hline 6 & $\begin{array}{l}\text { I feel stressed when I go } \\
\text { outside on a new route. }\end{array}$ & $11.8 \%$ & $38.2 \%$ & $8.8 \%$ & $26.5 \%$ & $14.7 \%$ \\
\hline
\end{tabular}

Table 6 shows that persons having visual impairment are less sure about their understanding and mental manipulation of spatial concepts. More than $80 \%$ of persons with visual impairment consider the acquisition of knowledge of an environment's structure realities as an achievement. Almost $70 \%$ of them take the task of interacting the outer world and traveling independently as the greatest challenge. Almost 50\% of them can move independently. This reflects the strong need to improve the self-confidence of persons having visual impairment. Contrary to this, there is less percentage of respondents who use the same familiar routes for same place and get stressed while adopting a new route.

\section{Discussion}

Major findings of the study reveal that persons having visual impairment rely on audition, haptics, and usage of assistive devices to gain the knowledge of spatial environments. This finding has been supported by studies conducted in other countries as well. Lahav and Mioduser (2003) suggested in the concluding remarks of their case study on using a haptic virtual environment that work with a multi-sensory virtual environment supported blind people's construction of spatial cognitive maps and, consequently, their navigation in real environments. Moreover, the study points out the physical barriers of built environments like pavement, furniture, construction/repair, irregular, uneven or broken surface, Lack of railing, and weather as big factors those affect independent movement and spatial cognition skills.

This study finds a less percentage of respondents who use the same familiar routes for same place and get stressed while adopting a new route. These findings of this research contradict to the findings of Passini et al., (1990). When traversing geographic space many blind people adhere to familiar, known routes, as exploration can be stressful, introducing disorientation and subsequent anxiety (Passini et al.,1990).

\section{Conclusions}

Vision is the most effective sense for gaining spatial relational information, but people having visual impairments can use language, audition, haptics, as well as awareness of flow and motion for the purpose of gaining a direct or indirect awareness of their geographic environment. An investigation of cognitive mapping skills of persons with visual impairment about their geographic environment is 
extremely worthwhile. It has considerable practical and theoretical worth; by providing necessary information about how to enhance orientation and navigation; provision of baseline of information about existing navigation strategies to design navigation aids; suggestions for improvement and modification of physical environments; and information about the role of sensory experience in cognitive mapping. The research presented shows some of the issues that need to be addressed. However, there is always a need of a holistic approach to bring insight, understanding and tangible benefits to persons having visual impairment.

\section{Recommendations}

All aspects of the 'human environment behavioral interface' need being investigated, as they are all interlinked. To increase the theoretical validity of application of cognitive maps to people with visual impairments, drawing on wealth of cognitive mapping is needed in psychology, planning, geography, cognitive science and so on. There is a pressing need for the application of cognitive mapping to real world practical situations. There is a strong need to provide better haptic information and provision of audio haptic maps and models of built environments. There is a strong need for the development of orientation and navigation aids to be more supportive and address the more macro problems of route planning, geographic orientation and way finding. There is a need to modify existing environments to enable better access for visually impaired people. This study addressed a small sample and since the study was conducted in Lahore, it has not the capacity to be a representative sample of the whole population of persons having visual impairment in Pakistan. Further studies with an enlarged sample drawn all over the country and using qualitative method should be conducted.

\section{References}

Brayda, L. Leo, F. Baccelliere, C. Vigini, C.\& Cocchi, E. (2019). A Refreshable Tactile Display Effectively Supports Cognitive Mapping Followed by Orientation and Mobility Tasks. A Comparative Multi-modal Study Involving Blind and Low-vision Participants Workshop Presentation MAHCI '19, October 25, 2019.

Bruce, I., McKennell, A. \& Walker, E. (1991). Blind and Partially Sighted Adults in Britain: the RNIB Survey, Vol. 1, HMSO, London.

Edelsberger, L., et al., (2000). Defektologický slovník. Praha: Nakladatelství H\&H. ISBN 8086022-76-5

Fletcher, J. F. (1980). Spatial representations in blind children: development compared to sighted children. Journal of Visual Impairment and Blindness.74, 381-385.

Golledge, R. G. (1993). Geography and the disabled: a survey with special reference to vision impaired and blind populations. Transactions of the Institute of British Geographers 18, 63-85.

Guerreiro1. J, Ahmetovic1.D, Kitani. K. M, Asakawal, C. (2017). Virtual Navigation for Blind People: Building Sequential Representations of the Real-World.ASSETS'17, Oct. 29Nov. 1, 2017, Baltimore, MD, USA.

Jacobson, D. (1998). Cognitive Mapping Without Sight: four preliminary studies of spatial learning. Journal of Environmental Psychology. 18 (3). 289-305.

Juurmaa, J. (1973). Transportation in mental spatial manipulation: a theoretical analysis. American Foundation for the Blind Research Bulletin. 26, 87-143.

Kuipers, B. (1997). The spatial semantic hierarchy for human and robot cognitive maps. Paper presented at Association of American Geographers, 1 April, 1997 Fort Worth, TX.

Lahav, O. \& Mioduser, D. (2003). A blind person's cognitive mapping of new spaces

Majerova,H. (2014). The aspects of spatial cognitive mapping in persons with visual impairment. Procedia - Social and Behavioral Sciences. 174. 3278 - 3284.

Millar, S. (1988). Models of sensory deprivation: The nature/nurture dichotomy and spatial representation in the blind. Journal of Behavioural Development. 11.69-87.

Nancy E. Guerrón, Antonio C. José J. Serrano Olmedoa, Carlos M. (2020). Sensitive interfaces for blind people in virtual visits inside unknown spaces. International Journal of Human- 
Computer Studies. 133 (13). DOI:10.1016/j.ijhcs.2019.08.004

Papadopoulosa, K. Baroutib, M. \& Koustriavac, E. (2018). Differences in Spatial Knowledge of Individuals With Blindness When Using Audiotactile Maps, Using Tactile Maps, and Walking. https://doi.org/10.1177/0014402918764300

Passini, R., Proulx, G. \& Rainville, C. (1990). The spatio-cognitive abilities of the visually impaired population. Environment and Behaviour. 22. 91-118.

using a haptic virtual environment. Journal of Research in Special Educational Needs. 3 (3),172-177. 